\title{
Using participatory action research to operationalize critical systems thinking in social-ecological systems
}

\author{
Madelon Eelderink $^{1,2}$, Joost M. Vervoort ${ }^{1,3,4}$ and Frank van Laerhoven $^{1}$
}

\begin{abstract}
We present a research approach that seeks to develop and strengthen participatory action research (PAR) when applied in social-ecological systems (SES) by combining it with critical systems thinking (CST). This research approach responds to the urgent societal need to move beyond predefined project framing in development projects. While PAR acts as a basis for operationalizing participatory research processes, CST supports PAR by including explicit questions about system and problem boundaries. We first present this approach in the context of existing approaches and then go on to illustrate it by investigating a SES case study of a marine system on the Caribbean Saba Island as part of a project to protect sharks from extinction. The case study illustrates that strengthening PAR with the explicit framing questions used by CST combines the strengths of these two approaches. This combination allows participants: (1) to (re)frame the problem definition and scope as perceived by the different stakeholders, and (2) to find, co-create, and implement viable solutions with local stakeholders to improve a SES based on local needs and diverse stakeholders' perspectives on potential solutions.
\end{abstract}

Key Words: Caribbean; critical systems thinking; fisheries; marine ecosystems; participatory action research; social-ecological systems

\section{INTRODUCTION}

Social-ecological systems (SESs) involve multiple stakeholders with widely diverse interests and perspectives on problems and solutions. Such actors often have incomplete understandings of the functioning of the entire system. As a result, problem and solution definitions are often diverse, contradictory, and unclear, and the achievement of one goal may cause challenges for other stakeholders. However, many nongovernmental organizations (NGOs) and governments engage with challenges in socialecological systems using preexisting problem framings (Cuppen 2012, van Laerhoven and Andersson 2013), aiming to convince other parties of the validity of the organizing actor's perspective on problems and solutions (Eelderink et al. 2017). This situation poses a challenge because such preexisting problem framing may miss important underlying or contextual challenges that should be of primary concern to those exploring interventions to solve the problem. Moreover, failure to explore and embrace the diversity of perspectives may hinder proper communication among stakeholders and may lead to unproductive conflicts in which stakeholders are prone to stick to their own perspectives (van Eeten 1999, Cuppen 2012, Watkins et al. 2018). Therefore, when a tightly predefined problem framing, objectives, and project boundaries are developed without understanding the systemic challenges and opportunities and their interrelatedness, project failure often follows, especially when the project addresses messy or unstructured problems within SESs (Cuppen 2012, Midgley 2016, Helfgott 2018, Watkins et al. 2018).

To avoid such limiting predefinitions and to move toward improving SESs in terms of resilience with and for all actors involved, approaches are needed that: (1) are conscious of how SESs are being framed by different actors, and (2) operationalize the development of system understanding and implement potential solutions in an inclusive, participatory manner. In addition, Helfgott (2018) has advocated moving from problem- based to strength-based approaches, building on community strengths focused on "empowering communities to foster positive change from within". Tàbara et al. (2010) offer a four-step pragmatic procedure for the transformation of systems called the "climate learning ladder". It addresses: (step 1) perceptions and frames about situations and awareness of (climate) risks, vulnerabilities, and opportunities and the need to change; (step 2) incentives, sanctions, and motives for such change; (step 3 ) the means and resources to be able to make such change; and (step 4) which institutions are needed to ensure sustainable social learning and action. Weaver and Rotmans (2006) offer an integrated sustainability assessment that includes problem coframing and solution development.

Here, we describe an inclusive, open, and reflexive approach to identifying problems and solutions in a SES and to cocreating community action plans (CAPs) to improve SESs in terms of resilience from the perspectives of multiple system actors. Our approach is comparable to existing approaches that seek to integrate systems thinking and action, but our starting point for developing this connection is different. Whereas the work of Weaver and Rotmans (2006), Tàbara et al. (2010), and Helfgott (2018) departed from systems thinking, we start from participatory action research (PAR). PAR is a strong tradition of research that focuses on the full integration of and iteration between action and research (e.g., Stringer 2014, Migchelbrink 2018). We seek to strengthen the ability of PAR to engage with the definition of systems, problems, and solutions within complex SESs. This is done by integrating critical systems thinking (CST) into PAR because CST poses explicit questions about system and problem boundaries that can be integrated into PAR processes. We first develop this combined approach conceptually and outline its benefits. We then apply this approach to a case study on Saba Island (a special municipality of the Netherlands in the Caribbean) in 2016 for a project of the Dutch Caribbean Nature

${ }^{1}$ Environmental Governance, Copernicus Institute of Sustainable Development, Utrecht University, The Netherlands, ${ }^{2} 7$ Senses, The Netherlands (www.7sens.es), ${ }^{3}$ Environmental Change Institute, University of Oxford, ${ }^{4}$ Research Institute for Humanity and Nature, Kyoto, Japan 
Alliance, which was originally framed as "saving sharks from extinction". We draw lessons on the implementation of CSTempowered PAR. We end by proposing avenues for future research based on our findings.

\section{THE DANGERS OF PREFRAMED DEVELOPMENT INTERVENTIONS}

Over the past few decades, numerous development projects have failed to meet the needs and priorities of local beneficiaries, often related to a limited understanding of the local SES (e.g., Sirolli 1998, Douthwaite et al. 2017, Watkins et al. 2018). Although there are many additional reasons for the failure of such development projects, one major pitfall is that local NGO dependence on financial assistance from donors makes them prone to stick with the tightly predefined development goals of their donors, leaving them with no space to adapt development projects to the local needs and social-ecological and cultural contexts in which the project is to be implemented (Amutabi 2006, Risal 2014, Gent et al. 2015). This problem is often combined with a limited understanding of the SES, including social-cultural, economic, biophysical, power, and other dimensions in which the project is embedded, which often results in a mismatch between the services provided by the NGO and the beneficiaries' needs and priorities (Amutabi 2006, Risal 2014). These challenges seem to indicate that the lack of an open, reflexive systems perspective, i.e., understanding the local social-cultural and social-ecological contexts, could lead to project failure or unintended negative consequences (e.g., Wilson 2017).

\section{INTEGRATING SYSTEMS FRAMING IN PARTICIPATORY ACTION RESEARCH}

To help overcome the issue of limiting problem framings leading to the failure of development projects, we propose to strengthen the ability of PAR to engage specifically with systems framing in SESs by combining PAR with CST. In this approach, PAR, a research tradition that already focuses on shared understanding and problem solving through collaborative action (e.g., Stringer 2014, Migchelbrink 2018), is empowered by integrating more robust systems framing questions derived from CST. Here, we characterize SESs as the types of system in which CST-enabled PAR offers unique benefits and then discuss PAR and CST as building blocks for our combined approach.

\section{Social-ecological systems}

A systems perspective is crucial to engage with the dynamic, complex, and cross-scale challenges that characterize systems in which human well-being is tightly linked to the natural environment (Apgar et al. 2017b). The SES framework (Ostrom 2007) serves as an analytical tool with which to study and fully appreciate system dynamics in coupled human-nature systems. It recognizes system components, i.e., resource systems, resource units, actors, and governance systems; system interactions that take place in so-called focal action situations; and system outcomes and feedbacks that result from these interactions. SES research sees human and natural systems as fundamentally integrated and studies the resilience of such integrated systems, aiming to understand nonlinear dynamics across multiple system levels, scales, and dimensions (Cash et al. 2006, Folke et al. 2010, Vervoort et al. 2012). However, SESs research does not inherently foster the development of a stakeholder-driven, reflexive systems framing or the implementation of well-fitted solutions to improve a SES for humans and nature.

\section{Participatory action research in social-ecological systems}

PAR offers many benefits for attempts to overcome the preframing of development problems by single organizations such as funders or policy makers. PAR is an action-based research method that fosters reflection and collective social learning (PahlWostl and Hare 2004, Apgar et al. 2017a,b), equity among different stakeholders (Apgar et al. 2017b), empowerment of the disempowered, and community-based action (e.g., Stringer 2014).

Globally, numerous PAR projects are conducted in many different arenas, characterized as strength and values based, action oriented, and participatory (Apgar et al. 2017a). Rather than either delivering a research report as an end product or implementing development programs without prior research on the problem context and opportunities for action, PAR uses research results as a means to trigger community action and vice versa. Through coresearching the problem context and potential solutions with stakeholders and sharing results with them during the PAR process, PAR opens up space for stakeholders: (1) to understand the entire system in which the problem is embedded, rather than solely the proximate problem context; (2) to understand the problem context from the perspective of other stakeholders, triggering social learning, a cooperative mindset, and innovation power; and (3) to cocreate and implement a strategic plan based on stakeholder intrinsic motivation and needs, which tackles the problem by improving the system in which the problem is embedded. Framing and coresearching the problem context and community assets (such as manpower, resources, past successes, and existing initiatives) with the involved community brings the knowledge of different stakeholders together to help cocreate the best fitting strategies among them. This strength-based aspect of PAR is what Helfgott (2018) advocates as the fuel for community empowerment. Moreover, this triggering of innovative power reaches beyond the creative capacity of each stakeholder individually. This way, PAR has the potential to unlock innovative thinking, willpower, and a cooperative mindset among those involved in the process to bring positive change into the system, leading to results that often reach beyond previously set goals as the codesigned initiatives reinforce each other and the system as a whole improves.

PAR has been researched as a suitable methodology to operationalize SESs thinking. Using PAR in a SES context has been connected to the fostering of learning among stakeholders (Trimble and Lázaro 2014), capturing and addressing complexity in science and society (Shirk et al. 2012), and increasing resilience (Ballard and Belsky 2010). Case studies combining SES thinking and PAR overall conclude that a PAR approach is a valuable tool for environmental learning (e.g., Ballard and Belski 2010, Shirk et al. 2012, Trimble and Lázaro 2014, Apgar et al. 2017a,b); however, the extent to which learning can actually promote system change and greater resilience must also be understood in context, especially in terms of political realities (e.g., Ballard and Belski 2010, Apgar et al. 2017a,b). PAR approaches often do not include specific questions tailored to the explicit definition of SESs and their associated challenges and opportunities. To empower PAR methodology in terms of system definition, we turn to CST. 


\section{Critical systems thinking in social-ecological systems}

Elucidating multiple perspectives, and possibly conflicting views, on system and problem boundaries has been argued to create mutual understanding between those holding varying perspectives (Midgley 2016) and to encourage social learning among multiple stakeholders (Pahl-Wostl and Hare 2004, McCarthy et al. 2011, Cuppen 2012). To take a systemic approach to SESs challenges, yet critically reflect with stakeholders on the boundaries used to investigate them, the use of CST has been proposed (Midgley 2016). CST is an approach to scientific and practical inquiry that holds a primary commitment to a systemic approach and human emancipation; it is grounded in critical theory and emancipatory and pragmatic philosophies (e.g., Ulrich 1993, Mc Carthy et al. 2011, Stephens 2013), and these traits distinguish it from more general ideas of systems thinking (Raymaker 2016).

Raymaker (2016) states that CST has challenged organizational leaders and researchers to attend to power and human emancipation (Flood 1990, Flood and Jackson 1991; Jackson 1990 as cited in Raymaker 2016). From this challenge, two CSTinformed methods have been developed: critical systems heuristics (Ulrich 1993), and boundary critique (Midgley 2000, Raymaker 2016). Both CST approaches challenge practitioners to reflect critically on their assumptions, to include those that are involved in as well as affected by the issue in the process, and to determine the agenda based on local perspectives rather than top-down led agendas. While these CST approaches stimulate reflexive and participatory thinking, CST seems to lack a methodological approach to operationalize its outcomes (Midgley 2000, Raymaker 2016). To fill this void, we propose to bring in PAR.

Several studies have applied CST to SESs, concluding that the combination of a SES approach and CST helps in defining the boundaries of a problem context and in rational planning within complex SESs (e.g., Ulrich 1993, McCarthy et al. 2011, Midgley 2016). A key paper for our purposes is Helfgott's (2018), in which the author combines the notions of resilience (strongly related to SES research, but also more widely applicable to complex systems) and CST and operationalizes them in a context of stakeholder participation through community operations research. Community operations research is related to PAR, and the combination of resilience, CST, and community operations research is therefore a highly relevant point of comparison for our study.

\section{Combining participatory action research and critical systems thinking in other fields}

Several studies conducted outside of the SESs domain emphasize the value of using PAR together with CST in enacting successful change in the interest of local communities under conditions of uncertainty (e.g., McIntyre-Mills 2008, Stephens 2013, Ariyadasa and McIntyre-Mills 2015). As such, PAR is used as a way to operationalize CST and to move from problem analysis to intervention. Combined PAR-CST approaches include community-based participatory research (Raymaker 2016), research in development (Douthwaite et al.2017), and community operational research (Midgley 2016, Helfgott 2018). There are several commonalities to PAR and CST approaches. They acknowledge the need to develop effective ways to manage inquiry in "messy" areas (Raymaker 2016:409) and intractable (Douthwaite et al. 2017) or complex (Midgley 2016) problems. They value human emancipation, systemic perspectives, and complementarism on multiple levels. They start in a broader context in which different stakeholders can find shared visions, leading to mutual understanding of perspectives, greater motivation, and ownership of the emerging agendas (e.g., Cuppen 2012, Apgar et al. 2017a,b, Douthwaite et al. 2017). They complement each other in that CST uncovers complexity, whereas PAR generates strategies for engaging with complexity (Midgley 2016, Raymaker 2016). Concluding from the literature outside of SESs and the use of either PAR or CST in SES, it seems that the combination of CST and PAR offers potential for use in solving complex issues within SESs.

In summary, we conclude that: PAR has been recognized as a powerful approach to achieve more inclusive engagement with SESs challenges; CST has been used to study SES problems in a more reflexive, participatory manner; and PAR has been linked with CST as a way to follow systems understanding with interventions in fields outside of SES research. A logical next step, then, is to use CST and PAR together to tackle problem framing in SESs. We argue that the most productive way to do this is to integrate CST-based questions into existing PAR approaches to make the focus on systems definitions in PAR more explicit for all involved. We will discuss whether and how the approach presented here may complement existing, comparable approaches that have started with CST and integrated PAR elements in their processes (Weaver and Rotmans 2006, Tabàra et al. 2009, Helfgott 2018).

\section{AN APPROACH TO COMMUNITY PROBLEM SOLVING IN SOCIAL-ECOLOGICAL SYSTEMS}

Here, we present a cycle of iterative, reflexive stages that integrates CST into a PAR approach specific to SESs. By "community", we mean all involved stakeholders of the issue under research. We refer to this integrated approach as critical action research in SESs (CARS).

\section{Stage 1. Orientation}

We refer to the person executing the CARS approach as the "practitioner" (singular), although CARS practitioners may also work in teams. In the orientation stage, the practitioner prepares the approach and builds rapport on location. This stage breaks up the limitations of theoretical reasoning and is the first step towards what Ulrich (1993) calls "identifying the normative content", i.e., the value-laden premises and life-practical implications of the propositions it helps to find.

a. Preliminary PAR design: An initial, preliminary PAR structure is outlined by the practitioner, focusing on a broadly defined draft objective, main PAR question, subquestions, stakeholders who should be involved, methodology, and concepts to be defined. This structure is to be revised with stakeholders at the first checkpoint (see Stage 1d).

b. Rapport building and training: Once on location, the practitioner introduces themself and the CARS to the community, identifies coresearchers from diverse member or actor perspectives in the community, and establishes a basic relationship with community members. If applicable, local stakeholders will be trained in the chosen set of PAR methods.

c. Multistakeholder system framing of the SES using CST: The practitioner conducts informal interviews to frame the system in which problem definitions are embedded, based on different 
stakeholder perspectives, using (1) the principles of SESs thinking and its four components (resource systems, resource units, actors, and governance systems; Ostrom 2009) as a basis for these interviews; and (2) critical systems questions to help establish who should be involved and how the system should be bounded. A first set of critical systems questions (Ulrich 1993) that helps to identify the four SES components is as follows.

- Who is or ought to be the client of the system to be designed or improved (S), i.e., who belongs to the group whose purposes (interests and values) are served?

- What is or ought to be the purpose of $\mathrm{S}$, as being measured not by the declared goals of the designers but by the design's actual or potential consequences?

- Who is or ought to be the decision maker, i.e., who has or should have the power to define and change S's measure of improvement?

- Who is or ought to be involved as planner or designer of $S$ ?

- Who belongs or ought to belong to the witnesses representing the concerns of those affected by $\mathrm{S}$ but not involved in its design, including those who cannot speak for themselves because they are handicapped, unborn, or part of nonhuman nature?

- What worldview actually underlies or ought to underly the design of S? Is it the worldview of (some of) the involved or of (some of) the affected?

The answers to these questions help to refine the PAR design based on the stakeholders' first shared perspectives (Stage 1d) and form the basis of system exploration (Stage 2).

d. First checkpoint, community PAR design: This first system framing is reviewed with local stakeholders. Adaptations are then made to the preliminary PAR design, which then becomes the operational community PAR design.

\section{Stage 2. System exploration}

The practitioner explores the issue addressed in the PAR design and its context from the perspective of multiple stakeholders. Now that the system boundaries are set, its content can be explored in more depth.

a. Data collection: The practitioner explores the SES in which problem definitions are embedded.

- i. Context: The practitioner explores with local stakeholders the issue's historical, social-cultural, social-ecological, and legal contexts, its causal relations, and the power and social relations among stakeholders using the SES framework (Ostrom 2009).

- ii. Current and desired situations: Using the critical systems questions, the current situation and the desired situation from the perspective of multiple stakeholders is mapped and compared, further defining the system boundaries where necessary. CST questions from Stage 1c are explored further, as well as the following additional questions (Ulrich 1993): What is or ought to be S's built-in measure of improvement, as judged by the trade-offs accepted with respect to conflicting purposes?
- What components (resources and constraints) of S are or ought to be controlled by the decision maker, that is, what conditions of successful planning and implementation of $\mathrm{S}$ are or ought to be under the decision maker's control?

- What resources and conditions are or ought to be part of S's environment, i.e., not controlled by the decision maker?

- What kind of expertise is or ought to be considered in the design of S, i.e., who is or ought to be considered an expert and what is or ought to be their role?

- Who or what is or ought to be assumed to be the guarantor of S, i.e., where do or ought the involved seek some guarantee that the design will be implemented and will secure improvement?

- To what extent and in what way are the affected given or ought to be given the chance of emancipation from the premises and promises of the involved? Are they or ought they be treated not only as means but also as ends in themselves? iii. The "gap" and the "need": Based on the comparison of current and desired situations, the gap between them is turned into a common shared need. $i v$. Motivations: The values and intrinsic motivations of each stakeholder to reach their desired situation are identified. v. Assets: Strengths, opportunities, and social capital of the community and involved institutions are identified to explore how they can fulfill the requirements and overcome the barriers for reaching the desired situation.

b. Second checkpoint, analysis: The practitioner analyzes and compares the results of the previous stages and different PAR methods used.

Stage 3. Insights sharing and solution identification

Based on insights from Stage 2, stakeholders identify a (combination of) mutually agreed upon solution(s).

a. Visualization of results: The practitioner creates an appropriate overview of the findings to be shared with stakeholders.

b. Third checkpoint, insight sharing: The practitioner presents the overview of findings so far to the community and facilitates reflection. This process facilitates knowledge cocreation and social learning among stakeholders: they learn about the SES researched, recognize their perspectives, and get an understanding of other stakeholders' perspectives. Any missing information is added to the overview of findings so far until the shared vision is clear for all involved.

c. Priority ranking and solution identification: Stakeholders connect the problem context, assets, and the first solutions mentioned to identify a range of solutions to the issue(s) and to add concrete ideas or elements to those solutions. Stakeholders rank those solutions according to applicability, urgency, and importance using insights from previous stages and identify and select the most appropriate solution(s).

\section{Stage 4. Action plan cocreation}

Stakeholders cocreate a concrete CAP.

a. Fourth checkpoint, ethical and legal appropriateness: The practitioner checks with other actors whether prioritized solution (s) are ethical and legally appropriate. 
b. CAP cocreation: The practitioner and local stakeholders set up a strategic CAP through which each stakeholder can contribute to the desired situation from their own intrinsic motivation and set a starting date for implementation.

c. Roles and responsibilities: For each activity of the CAP, roles and responsibilities are divided among stakeholders.

\section{Stage 5. Formalization and transferal}

The CAP is formally accepted by and handed over to its executors and other involved stakeholders.

a. Fifth checkpoint, reflection on roles and responsibilities: The practitioner checks individually with all involved whether they agree and feel comfortable with their roles and responsibilities.

b. CAP formalization and transferal: The CAP is formally acknowledged by the community, local government, and other institutions, and officially handed over to confirm ownership over the CAP.

c. Celebration: The development and kickoff of the CAP is celebrated as well as each of its (first) successes.

d. Implementation: The appointed and responsible stakeholders start executing the activities of the CAP at the determined date(s).

\section{Stage 6. Monitoring}

During its execution, local stakeholders monitor and reflect on their CAP.

a. Activities monitoring: Local stakeholders keep track of their activities in terms of successes and challenges and inform the practitioner.

b. Sixth checkpoint, reflection on activities: The practitioner and stakeholders reflect on the outcome of the activities and determine strategies to tackle or bypass any emerging challenges.

c. Adaptation: Where necessary, local stakeholders adapt the CAP to increase project uptake and success.

\section{Stage 7. Evaluation}

After (most) activities of the CAP are executed, stakeholders evaluate the outcomes of each activity and its impact on the SES.

a. Seventh checkpoint, reflection on PAR process and outcomes: Using PAR and other evaluation techniques, the practitioner and local stakeholders reflect on the PAR process and the CAP's outcomes.

b. Upscaling: Based on stakeholders' perspectives on CAP outcomes, using PAR techniques, they identify new needs and ways to adapt or upscale the CAP where necessary and appropriate.

Although we have described the CST-PAR approach as a seemingly linear process, it is in fact an iterative process in which practitioners move back and forth between stages and substages, when required. We illustrate this process using the example of Saba Island.

\section{TESTING THE CRITICAL ACTION RESEARCH IN SOCIAL-ECOLOGICAL SYSTEMS APPROACH: SABA CASE STUDY}

To illustrate the relevance and potential of the CARS approach, we present a 7-week case study (after a 4-day preliminary orientation study) of a project called "Save our Sharks" conducted on the island of Saba between July and August 2016. To describe chronologically how PAR methodology was combined with CST and SES thinking at various moments over time and outline how each subsequent step of the process was adapted based on the outcomes of previous steps, we describe the methods and results of the case study together. This step-by-step description is crucial to highlight the essence of our combined approach: subsequent steps involve participatory system framing, but also participatory method selection, prioritization of solutions, and cocreation of a CAP, which means that the results of each step have to be described to understand the logic behind the rationale underlying the design of the subsequent stage.

The main outcome of the Saba case study was a fishers' agreement on "seasoning for redfish",[1], i.e., establishing a closed season for redfish to revive the redfish population, which the fishers claimed had been declining at an alarming rate over the preceding 15-20 years. The agreement was cocreated by local Saban fishers with input from other stakeholders such as divers, experts, local government, and nature organizations. The fishers' agreement was an unexpected outcome, considering the goal of the involved nature organizations was to save sharks from extinction. However, increasing the redfish population is an indirect contribution to saving sharks, that was cocreated by local stakeholders based on their needs and intrinsic motivation. According to local divers, experts, and literature, an increased redfish population contributes to a better living environment for sharks (NIWA Taihoro Nukurangi, https://niwa.co.nz/fisheries/ecosystem-influenceson-snapper/life-cycle/adult). We next describe the steps that led to this outcome. The numbers in parentheses refer to the stages and activities described above in the CTS-PAR approach.

\section{Stage 1. Orientation}

Prior to fieldwork, a preliminary PAR design (1a) was created. On location, as part of rapport building (1b), the research project was introduced in church and informal settings. A local fisherman was appointed and trained to assist in the PAR project (1b). Through snowball sampling, informal conversations with local stakeholders were held using SES thinking and a first set of CST questions (1c). The results revealed that, among Sabans, there was little interest in saving sharks; however, many other challenges regarding the marine ecosystem were reported. Therefore, the scope of the research was broadened from sharks to the marine ecosystem to give all stakeholders space to share their views within this broader SES. As a first checkpoint (1d), based on the first outcomes, the preliminary PAR design was adapted with local stakeholders to a suitable and workable community PAR design.

\section{Stage 2. System exploration}

In this stage, participants aimed to understand the context and main concerns with regard to the marine ecosystem from the perspective of different stakeholders.

\section{Interviews, seasonal diagrams and focus groups}

Using snowball sampling, semistructured interviews were conducted with respondents from 15 different stakeholder groups $(N=56)$, including fishers and their families (spouses, children), divers, the Saba Conservation Foundation, government and church representatives, local and international experts, elderly people, and others. Homogeneous focus groups were conducted with Saba Conservation Foundation staff $(N=7)$ and divers $(N$ 
$=4)$. The aim of the interviews and focus groups was to explore: the context of problems addressed by each stakeholder using the SES framework (2a.i), the current and desired situations as perceived by the different stakeholders using CST questions (2a. ii), the needs of the different stakeholders as derived from the gap between the current and desired situations (2a.iii), intrinsic motivations to change the system (2a.iv), and assets that could be used to change the system (2a.v). Interviews and focus groups were very open in structure and content to give respondents full freedom to talk about what they considered relevant. After each interview, licensed fishers filled in (anonymous) seasonal diagrams to indicate how many fish and lobster they catch each month of the year. Analysis, the second checkpoint (2b), was done using thematic content analysis and framework analysis (Green and Thorogood 2014).

\section{Results}

Urge to increase the redfish population

All interviewed fishers, as well as other stakeholders, expressed their concern with regard to the decline of redfish over the preceding 15-20 years. This concern is exemplified by the following quotations.

\section{Sometimes fish is low, especially redfish. We can say we have a good catch when we have 200 kilos of fish. But even with the full moon we don't get that much, we have like 150 kilos. A couple of years back we had much more. [...] I think it is because of overfishing. (Fisher). \\ In my work as a cook I see the snapper [i.e., redfish] becoming smaller and smaller. The cause is overfishing I suppose. (Cook).}

The fishers' proposed solutions for the problem of declining redfish included, most prominently, "seasoning", i.e., establishing a closed season for redfish. However, opinions on how to season differed in terms of, for example, length and location, causing major hiccups in the establishment of an agreement on seasoning since redfish had started to decline. In addition, fishers were worried about their income during the closed season for redfish. All licensed fishers also fish for lobster, yet lobster income alone does not suffice to support their families.

\section{Worries about the lionfish plague}

In addition, divers $(N=3)$, fishers $(N=2)$, a cook $(N=1)$, a nature organization staff member $(N=1)$, and a tourist sector representative $(N=1)$ independently claimed that lionfish are a big threat to (red)fish, coral reefs, and the marine ecosystem as a whole. The following quotation exemplifies this impression.

Overfishing is the biggest threat to the redfish, then second comes the lionfish. They are an invasive species. [...] With these threats, within 10 years there will be no red snapper [i.e. redfish] anymore. (Fisher).

Some of the divers and nature organization staff spear-shoot lionfish. However, this activity does not suffice to control the population.

\section{$\underline{\text { Worries about coral reefs }}$}

Worries about coral reefs were expressed explicitly in seven comments, as well as five times as part of a general worry about the marine ecosystem, three times as part of fisheries, (i.e., creating more fish), three times in relation to sharks, and twice in relation to landslides. Such comments were contributed by a government representative $(N=1)$, Saba Conservation Foundation staff members $(N=2)$, a medical student $(N=1)$, divers $(N=6)$, a farmer $(N=1)$, a tourist officer $(N=1)$, and fishers $(N=2)$. Causal explanations ranged from global warming (climate change) to local algal growth, anchors, and landslides.

We can't control temperature, lionfish, hurricanes, etc., and that is what causes most damage to the coral. (Dive operator).

When rain comes, it [garbage, soil] flushes into the water. It kills the coral. Any bit of silt must be detrimental to marine life. (Farmer).

There is pesticides and herbicides, weed killers and pest killers, but it all ends in the ocean. (Farmer).

Numerous solutions were proposed, ranging from goat elimination programs and planting bamboo trees to rezoning the Marine Park ${ }^{[2]}$. However, these comments clarify the commonly shared worry about coral reefs in Saba territorial waters.

\section{Seasonal diagrams}

Fishers were asked to draw seasonal diagrams, from which it was learned that redfish spawn year-round and that catches are generally low from May to October.

Analysis (2b) of these first data sets revealed that there were several needs identified among different stakeholders with regard to the marine ecosystem and that there was intrinsic motivation to establish a closed season for redfish (fishers), to eliminate the lionfish plague (divers, fishers, and nature organizations), and to increase the shark population (mainly nature organizations). Few assets and solutions were mentioned by stakeholders to achieve these goals. Experts and literature confirmed that an increased redfish population and a reduced lionfish population have positive effects on the shark population and coral reefs because sharks prey on redfish but not on lionfish, and a reduced lionfish population also allows corals to recover, providing a range of ecological benefits for sharks (e.g., Albins and Hixon 2013, Roff et al. 2016; NIWA Taihoro Nukurangi, https://niwa.co.nz/ fisheries/ecosystem-influences-on-snapper/life-cycle/adult).

\section{Stage 3. Insights sharing and solution identification}

The third stage of the action research aimed to visualize the above results (3a), share those insights with stakeholders (third checkpoint, 3b) and determine what issues and corresponding solutions are given highest priority (3c). Based on our first findings, shared in a first focus group (fishers $N=11$, nature organization representative $N=1 ; 3 a$ ) for reflection (3b), it was decided with the local nature foundation and fishers to focus on facilitating the fishers in coming to an agreement for a closed season for redfish. Given the tense situation among fishers and between fishers and the local nature organization, an anonymous questionnaire was developed at the request of the fishers to identify the most valued set of solutions.

\section{Questionnaire}

A questionnaire $(N=12)$ was developed based on all outcomes from the individual interviews with the fishers. The questionnaire aimed to assess what measures fishers collectively considered most 
important (3c). The questionnaire consisted of all proposed solutions from the interviews, with options for prioritization of those solutions in the categories of: seasoning systems, additional measures, and alternative income. For each proposed solution, three options were provided and scored: "very important", 3 points; "important", 2 points; or "not important", 1 point; and the points were summed. In addition, a section of the questionnaire was dedicated to perspectives on the establishment of a fishers' organization to verify fishers' preferences (results not presented here).

Results

The highest score for the seasoning systems category was to close the entire Saba Bank for 4 months (score = 20). Eleven of the twelve fishers claimed that a maximum of four longlines should be allowed during the closed season. According to respondents, longlines allow fishing for redfish in a different, deeper area where nonthreatened redfish reside.

In the additional measures category, establishing a fishers' organization was most popular ( score $=35$ ), followed by throwing sharks back alive because they keep the reefs that redfish depend on healthy (score $=32$ ). Furthermore, fishers considered arranging duty free fuel from the government (score $=31$ ), patrolling for illegal fishing (score $=29$ ), and using larger mesh sizes for their traps, which allows smaller fish to escape (score $=$ 28), as most important.

In the alternative income category, only fishing aggregating devices for mahi mahi, a species fished by some Saban fishers, was considered relatively important (score $=30$ ). There were few other types of alternative income mentioned during interviews, all of which scored relatively low.

After responding to this questionnaire, one diver proposed to experiment with lionfish-specific traps.

[catching] lionfish could be a good [alternative] income [for the fishers, for seasoning for redfish]. [...] So if we can get specific lionfish traps, then that could be a viable option. [...] There are specially designed traps now, which catch lion fish. It's done by a company called Frapper [Team Frapper, a U.S. organization experimenting with lionfish-specific traps]. They are definitely testing it now. I don't know when it's going to become official. (Diver).

On Saba, but especially on Sint Maarten, there is a market for lionfish because it is considered a delicacy.

\section{Second focus group with fishers}

The results of the questionnaire, along with previous results, were visualized in a Google Sheet (3a) and shared in the second focus group with fishers $(N=10)$ for reflection (3b) and solution identification ( $3 \mathrm{c})$. The aim of the focus group was, as indicated by the attending fishers, to come to an agreement for a closed season for redfish. After sharing the Google Sheet and seasonal diagrams (3a) and reflecting upon them (3b), priorities for seasoning options were set by the fishers (3c). Three significant observations characterized this focus group. First, instead of choosing the highest prioritized option of seasoning for four months, using seasonal diagrams outcomes, fishers decided together to extend this period to six months, starting April 2017 during redfish low season. Second, although fishers claimed that sharks were a nuisance to them, they acknowledged their importance and decided to include throwing sharks back alive after catching them in the agreement. Where seasoning for redfish is an indirect way to help save sharks from extinction, throwing back live-caught sharks is a direct way to save them. Third, after this focus group, fishers were standing on the dock as a group, having a beer together. Given the tense atmosphere at the start of this CARS, this camaraderie was remarkable.

\section{Stage 4: Action plan cocreation}

In this stage, we aimed to cocreate the CAP for a closed season for redfish.

\section{Reflection on the draft agreement}

As a fourth checkpoint, the rules that fishers set for this agreement were checked with the laws of the Exclusive Economic Zone to confirm their alignment (4a). After the prioritized measures were documented in a (draft) agreement $(4 \mathrm{~b})$, fishers $(N=12)$ were individually asked to reflect on it and sign when they agreed (5a and $b$ ). Three fishers who did not attend the meeting did not or did not fully agree with the clauses that were put together. In particular, the number of months to be seasoned turned out to be an issue.

\section{This ain't gonna make me happy. I am sure all fishermen want four months instead of six months. I will call all of them and let you know tonight. Then I would like to have a new meeting. (Fisher).}

That evening, the fisher in question called and stated that all fishers had agreed upon a closed season of four months. A new meeting (a focus group) was organized to discuss this change further and adapt the agreement where necessary (4b).

\section{Third focus group with fishers}

The third focus group with fishers $(N=8)$ was organized to discuss, adapt, and confirm the final set of clauses for the agreement ( $4 \mathrm{~b}$ and $\mathrm{c}$ ). At its opening, fishers stated again that they aimed to come to an agreement for a closed redfish season. Because of the tension that had developed over the number of months to season, the practitioner emphasized the goal of facilitating the process toward an agreement rather than pushing to a certain direction.

After reflection, fishers again concluded that seasoning for six months would be the best option, starting in April 2017. Clauses were adapted and concretized with fishers (4b). Then, all clauses were read out loud by the practitioner, to which all fishers one by one confirmed their agreement (4c). Based on these last adaptations from the fishers, the final version of the agreement was put together $(4 \mathrm{~b})$ and printed by the practitioner.

\section{Stage 5. Formalization and transferal}

During this stage, the agreement was formalized and prepared for its implementation from April 2017 onward.

\section{Reflection on roles and responsibilities}

Each fisher was approached separately to reflect on the latest version of the agreement (5a) and to confirm their role, commitment, and responsibility as a fisher to comply with the agreement, i.e., the closed season for redfish and subsequent sustainable fishing for redfish (5b). 
Focus group with Saba Government and a fisher

As a continuation of the roles and responsibilities phase (4c and $5 \mathrm{a})$, and formalization and transferal of the final agreement (5b), in the last week of the PAR, a final focus group was held with Island Council members $(N=3)$, the Griffier $(N=1)$, the Island Governor $(N=1)$, and a fisher $(N=1)$. All results from the PAR thus far were presented ( $3 a$ and $b$ ). Island Council members consulted the fisher on several subjects regarding fishing, seasoning, and (plans for) establishing a fishers' organization. Wishes, goals, and concerns from the part of the fishers were shared, leading to action points from the side of the government, regarding, among others, formalizing the agreement in the fishing licenses and supporting the fishers (4c). The fishers' agreement was officially handed over and signed by the Island Governor (5b).

\section{Celebration}

The formalization of the agreement was celebrated among the fishers, nature organization staff, an Island Council member, and the practitioner by toasting drinks at a local bar (5c).

\section{Implementation of the closed season for redfish}

To start the closed season for redfish, on 1 April 2017 (a few months after the practitioner had left Saba), fishers pulled out their redfish traps $(5 \mathrm{~d})$.

\section{Implementation of the lionfish trapping pilot project}

In early May 2018, the first lionfish traps were designed and launched in the water (5d) and are currently being tested.

\section{Stage 6. Monitoring and Stage 7. Evaluation}

Monitoring and evaluation were not part of this seven-week case study because the closed season began several months after the PAR concluded. Instead, we discussed with local stakeholders how the closed season for redfish could be monitored, controlled, and evaluated each year, and how each of the clauses in the agreement could be altered and adapted to new circumstances. Informal telephone conversations with fishers and other local stakeholders during the closed season ( $6 \mathrm{a}, \mathrm{b}$, and c) confirm that they complied to the rules of their cocreated agreement. Also, the first author monitored the development of the lionfish trapping pilot project (6a, b, and c).

\section{SABA CASE: FINAL OUTCOMES AND CRITICAL REFLECTION}

The Saba case describes (1) the process leading to the cocreation of a CAP to improve living circumstances for sharks through improving the marine ecosystem's balance, and (2) how solutions were cocreated for seemingly separate problems and translated into new economic incentives for nature conservation (Fig. 1).

The PAR began from the perspective of the involved nature organizations (Fig. 1, top circle), who expressed the urge to save sharks from extinction. However, Saban fishers showed no interest in shark-saving activities. Broadening the scope from saving sharks to improving the marine ecosystem opened up spaces for local stakeholders within this shared vision to express their concerns, ideal situation, and solutions on how to achieve that ideal.

The main outcomes from interviews and focus groups with several different stakeholders were the desire to increase the redfish population (Fig. 1, bottom left circle) and to tackle the lionfish plague (Fig. 1, bottom right circle). Solutions included: (1) a closed season for redfish to save them from extinction (proposed by mainly fishers), and (2) setting up a lionfish trapping pilot project (proposed by a diver), in which fishers fish for invasive lionfish using specific traps to mitigate the damage lionfish cause to coral and other fish types such as redfish, and which provides an alternative income for fishers during the closed season for redfish (Fig. 1, arrows). Because sharks depend on redfish and coral reefs (among other species) for their survival, rebalancing the marine ecosystem through increasing the redfish population and decreasing the lionfish population is expected to help save sharks, which serves the goal of the involved nature organizations (Fig. 1, arrows).

Fig. 1. Diagram of the interrelatedness of different perspectives within the Saba Island marine ecosystem (simplified version).

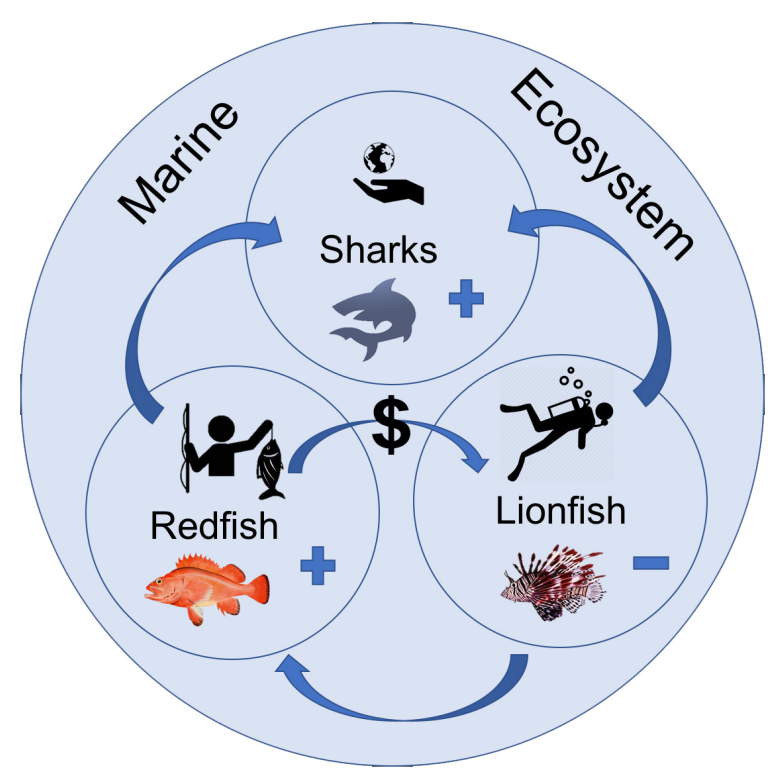

To check for rigor, we used measures to ensure credibility, transferability, dependability, and confirmability of the PAR, as described by Stringer (2014). First, to ensure credibility, different PAR methods were used, as well as different stakeholder perspectives (triangulation). Member checking was done, meaning that all results were shared with PAR participants to reflect upon and add to or change them where necessary. Diverse case analysis was applied, meaning that all stakeholders (or representatives thereof) were involved in the PAR. Concepts and ideas all came from participants (i.e., referential adequacy). Second, to ensure transferability, the PAR process and outcomes were reported and shared with involved nature organizations in a way that made replication of the PAR possible in other contexts. Third, to ensure dependability, all systematic procedures were followed carefully and were communicated to participants. Fourth, to ensure confirmability, all notes, voice recordings and transcripts, questionnaires, seasonal diagrams, and other materials were saved to prove that all events described here actually occurred.

Reframing the issue from sharks to the marine ecosystem, thereby using PAR combined with a social-ecological systems approach and CST, has shaped ground to cocreate a CAP in which economic 
incentives established new driving forces for conserving the marine ecosystem. First, it clarified which different mental models were used by different stakeholders to define the problem and potential solutions from their perspectives. Second, this process opened up the opportunity to find interrelations between problems and solutions. Third, sharing this system of coexisting mental models with the involved actors enabled processes of social learning and double loop learning (Sendzimir et al. 2018) as mutual understanding improved, and the process enabled a shift in mental models. For example, fishers were at first not interested in saving sharks, yet by the end of the process, in their agreement on seasoning for redfish, they took up a clause "not to catch sharks intentionally, and to throw unintentionally caught sharks back alive", which refers to a shift in their mental model.

To our knowledge, this is the first time fishers and other stakeholders have cocreated a CAP to improve the marine ecosystem from multiple angles. One fisher stated,

\section{We have been waiting for this [establishing a fishers' agreement for a closed season on redfish] for 20 years, since we realized the redfish is declining. Nobody has ever accomplished this, not even the experts. Now we have done it ourselves in just seven weeks.}

In the Saba case, facilitating local stakeholders in the process of cocreating solutions that fit their values and needs through this approach led to the establishment of ownership, pride, motivation, and willingness to cooperate.

In the design of projects in social-ecological contexts, we propose for practitioners to avoid imposing predefined boundaries. Rather, according to the CST approach, boundaries in SESs need to be probed to enable all stakeholders to share their perceived issues and options for improvement. This process leads to a synergistic way of problem solving without having to reach consensus among the different stakeholders.

The CST approach, i.e., elucidating the "what is" and "what ought to be" questions of critical systems heuristics, opened up spaces to reflect upon the gaps between what is and what ought to be from the perspectives of multiple different stakeholders and to define the boundaries of the SES.

Applying PAR in the Saba case enabled the operationalization of CST in the marine ecosystem SES through problem and scope identification, prioritization, and the codesign and implementation of a CAP to achieve the desired situation. Through the combination of a SES approach, CST, and PAR (now launched as CARS), fishers, in collaboration with other stakeholders, managed to establish a closed season for the endangered redfish. A replenished redfish population in turn leads to an improvement of the balance of the marine ecosystem and a better living environment for sharks, thereby indirectly complying to the goals of the involved nature organizations. Through the closed redfish season, combined with the lionfish trapping pilot project, stakeholders are cocreating new economic incentives for nature conservation.

\section{DISCUSSION}

We explored the benefits of using CST to inform and strengthen PAR to overcome development challenges associated with noninclusive, preframed problem approaches in development research and planning in SESs, which we call CARS. Our literature findings indicated that PAR had been combined with either CST (McIntyre-Mills 2008, Stephens 2013) or a SES approach (Ballard and Belski 2010, Trimble and Lázaro 2014) in specific cases; that CST and SES approaches had been linked to each other (Mc Carthy et al. 2011, Midgley 2016); and that PAR elements had been used to support SES-CST research (Helfgott 2018). Other comparable methods have combined more general systems thinking and participatory, action-oriented processes not rooted explicitly in CST-PAR combinations (Weaver and Rotmans 2006, Tabàra et al. 2009). This existing research demonstrated the benefits of these partial combinations and indicated that using CST elements to develop the new PAR approach specifically focused on SES challenges described here would have unique potential for reconsidering system boundaries and multistakeholder problem solving and action.

We demonstrated that this enriched PAR approach, dubbed CARS, in a case study on the island of Saba yielded synergistic results in a problem space defined in a participatory, reflexive fashion. In the case study, the combined approach was used to cocreate and implement solutions based on local needs and the local social-ecological context. This approach led to transdisciplinary, locally cocreated solutions to seemingly separate problems that also translated into new economic incentives for nature conservation. Through elucidating all stakeholder perspectives, needs, incentives, and local assets that can be used to enhance positive change, and through facilitating reflective cycles and the cocreation of community-specific action plans and respective institutions, this approach contributes to enhance local transformative capacities, e.g., by changing fundamental system interactions. This approach is in line with the climate learning ladder by Tàbara et al. (2010).

The Saba case illustrates that through applying the CARS approach, the different stakeholders, which included local nature organizations, fishers, and divers, could reach their own objectives while contributing to a broader system, i.e., the marine ecosystem, which also helped each of the separate stakeholders reach their objectives without the need to convince other stakeholders. A SES perspective was necessary to understand the interaction of stakeholders with the marine ecosystem of Saba territorial waters. CST was necessary to break open the predefined framing of saving sharks and move toward improving the marine ecosystem to give stakeholders space to come up with solutions that fit their values, needs, and objectives. The backbone of the approach, PAR, was necessary to learn from practical engagements and to operationalize the findings in a CAP to improve the marine ecosystem. These results suggest that the outcomes of the Saba case, i.e., the fishers' agreement on a closed season for redfish and the lionfish trapping pilot project as an alternative source of income, could not have been reached without this combined approach.

Furthermore, the Saba case provides some notable insights. First, in line with theory (e.g., Khanlou and Peter 2005, Stringer 2014, Migchelbrink 2018), having no strongly defined agenda as a practitioner contributed to a comfortable atmosphere between the practitioner and respondents. For fishers this openness was especially important because they expressed that they have had "laws pushed down their throats" by experts flying into Saba. 
Second, using no predefined knowledge framework about the system paved the way for asking questions, whereas experts may have taken knowledge, possibly wrongfully, for granted. Third, asking the fishers at the beginning of a focus group what they would like to achieve created a comfortable, open, and cooperative atmosphere, presumably because it emphasized that the practitioner had no conflicting agenda. Fourth, presenting results of the research, i.e., the multiple local perspectives on the problem and potential solutions, was highly appreciated by the fishers. It was confirmed by the local nature organization as well as the fishers themselves that the high attendance rate was achieved because the results of the research would be shared with participants, whereas normally they would be excluded from such knowledge sharing. Presenting codesigned knowledge contributed to a group dynamic that resembled dialogue and a cooperative mindset rather than antagonistic discussion.

Nevertheless, this study came with some limitations. First, given the short length of the case study, a full iteration of the entire process was not carried out. A longer case study could have led to further revision of the problem framing, and more of the stakeholders' proposed solutions could have been developed. In addition, more time could have led to increased capacity of stakeholders to repeat the iterative PAR cycle, e.g., to adapt the agreement in subsequent years to establish new closed seasons. Second, the set of questions from the CST approach has not been applied systemically. After the study, it was concluded that the "what is" and "what ought to be" questions were already part of a more open interview approach in PAR. Third, literature on SES, PAR, and CST solely and in paired combinations was so extensive that we could not analyze all of it. Fourth, the PAR methodology had to be adapted because not all participants agreed with the proposed methodology, i.e., a simulation game to test possible solution scenarios had to be changed into a questionnaire because participants preferred to remain anonymous. We therefore underline the prerequisite of flexibility as described in literature (e.g., Stringer 2014, Migchelbrink 2018). Fifth, we realize that the PAR process itself did not lead to gained trust among participants; rather, participants managed to find their own way of contributing to the marine ecosystem without having to rely on others they did not trust. Fifth, the lionfish trapping pilot project, which aimed to commence during the closed season, was delayed because of difficult-to-meet criteria from the financing party. More focus on local assets instead of external finance could have prevented this delay.

We recommend to explore further the development of PAR using CST and SES, conceptually as well as in new case studies. For theory development, more research is needed to identify the gaps and potential benefits of using this combined approach. For new case studies, the CST list of questions could be applied more systemically to elucidate power dynamics and leadership in the cocreation of new projects for nature conservation. Similarly, more elaborate and specialized interpretations of the SES approach could be used for questions and discussion points in a PAR approach for specific cases and purposes (Preiser et al. 2018) as well as social-ecological approaches focused on imagining and enacting transformation processes (Hebinck et al. 2018, Pereira et al. 2018) when transformative ambitions and needs exist.

For development actors, the CARS approach in the Saba case demonstrates that there are practical and effective alternatives to top-down problem and solution framing in development contexts (Amutabi 2006, Risal 2014). Broadening the context of the issue addressed opens up the space for local stakeholders to express their genuine concerns and ways to address them based on their intrinsic motivations. This process leads to solutions that go beyond the initial focus of a development actor. However, the ability to do this requires development actors such as NGOs and donor agencies to understand, and importantly, to trust that the CARS approach follows a different dynamic in which: (1) the broader SES is mapped out based on multiple stakeholder perspectives, (2) the solution remains unclear until the later stages of the action research, (3) the solution(s) may defy expectations, and (4) the solution becomes embedded in a CAP to improve the broader system with multiple stakeholders, rather than a unilateral top-down plan. If so, people can be moved, and move each other, to solve problems collectively in development contexts of SESs.

${ }^{[1]}$ Clauses in the fishers' agreement include the following. (1) To establish a fishers' organization, starting its development in August 2016 and aiming to be officially formed before the end of 2016. (2) To establish a closed season for redfish for six months for the entire Saba Bank from 1 April 2017 until 30 September 2017 , leaving room afterward for reflection and adaptation of the seasoning system for subsequent years based on the results of the 2017 seasoning system. (3) To set a limit of 25 redfish traps from 1 October 2017 until the next agreed upon closed season. (4) To allow a maximum of four vertical longlines for redfish per fishing boat during the closed season for redfish. (5) Not to catch sharks intentionally, and to throw unintentionally caught sharks back alive when using traps, longlines, fishing aggregation devices, and other methods because sharks they keep the marine ecosystem healthy. (6) To use bigger mesh sizes: All fishers will use $5 \mathrm{~cm}^{2}$ mesh wire for at least the doors of redfish traps. (7) To arrange patrolling for illegal fishing (meaning breaking these agreements) for foreign and local boats, in cooperation with the government and coast guard.

[2] More information about these proposed solutions can be provided by the authors upon request.

\section{Responses to this article can be read online at: http://www.ecologyandsociety.org/issues/responses. $\mathrm{php} / 11369$}

\section{Acknowledgments:}

This paper could not have been enriched with the case study without the Dutch Caribbean Nature Alliance (DCNA), which supported the participatory action research conducted by first author $M$. Eelderink on the island of Saba. We thank DCNA representatives for allowing Eelderink to conduct participatory action research for their "Save our Sharks" project, the Saba Conservation Foundation for facilitating her work, the Saban government and co-researcher and fisher Luke for their support during the fieldwork, and all respondents for their input and cooperation during the process. Finally, we thank Charlotte Ballard and Kyle Alexander Thompson for checking our use of English in this paper. 


\section{LITERATURE CITED}

Albins, M. A., and M. A. Hixon. 2013. Worst case scenario: potential long-term effects of invasive predatory lionfish (Pterois volitans) on Atlantic and Caribbean coral-reef communities. Environmental Biology of Fishes 96(10-11):1151-1157. https://doi. org/10.1007/s10641-011-9795-1

Amutabi, M. N. 2006. The NGO factor in Africa: the case of arrested development in Kenya. Routledge, New York, New York, USA. https://doi.org/10.4324/9780203960707

Apgar, J. M., W. Allen, J. Albert, B. Douthwaite, R. Paz Ybarnegaray, and J. Lunda. 2017a. Getting beneath the surface in program planning, monitoring and evaluation: learning from use of participatory action research and theory of change in the CGIAR Research Program on Aquatic Agricultural Systems. Action Research 15(1):15-34. https://doi.org/10.1177/1476750316673879

Apgar, J. M., P. J. Cohen, B. D. Ratner, S. De Silva, M.-C. Buisson, C. Longley, R. Bastakoti, and E. Mapedza. 2017b. Identifying opportunities to improve governance of aquatic agricultural systems through participatory action research. Ecology and Society 22(1):9. https://doi.org/10.5751/ES-08929-220109

Ariyadasa, E., and J. McIntyre-Mills. 2015. A systemic governance approach to an effective re-integration process for the institutionalized children in Sri Lanka: application of critical systems heuristics. Systemic Practice and Action Research 28 (5):429-451. https://doi.org/10.1007/s11213-014-9338-8

Ballard, H. L., and J. M. Belsky. 2010. Participatory action research and environmental learning: implications for resilient forests and communities. Environmental Education Research 16 (5-6):611-627. https://doi.org/10.1080/13504622.2010.505440

Cash, D. W., W. N. Adger, F. Berkes, P. Garden, L. Lebel, P. Olsson, L. Pritchard, and O. Young. 2006. Scale and cross-scale dynamics: governance and information in a multilevel world. Ecology and Society 11(2):8. https://doi.org/10.5751/ES-01759-110208

Cuppen, E. 2012. Diversity and constructive conflict in stakeholder dialogue: considerations for design and methods. Policy Sciences 45(1):23-46. https://doi.org/10.1007/s11077-011-9141-7

Douthwaite, B., J. M. Apgar, A.-M. Schwarz, S. Attwood, S. Senaratna Sellamuttu, and T. Clayton. 2017. A new professionalism for agricultural research for development. International Journal of Agricultural Sustainability 15(3):238-252. https://doi.org/10.1080/14735903.2017.1314754

Eelderink, M., J. Vervoort, D. Snel, and F. de Castro. 2017. Harnessing the plurality of actor frames in social-ecological systems: ecological sanitation in Bolivia. Development in Practice 27(3):275-287. https://doi.org/10.1080/09614524.2017.1291583

Flood, R. L. 1990. Liberating systems theory: toward critical systems thinking. Human Relations 43(1):49-75. https://doi. org/10.1177/001872679004300104

Flood, R. L., and M. C. Jackson. 1991. Total systems intervention: a practical face to critical systems thinking. Systems Practice 4(3):197-213. https://doi.org/10.1007/BF01059565
Folke, C., S. R. Carpenter, B. Walker, M. Scheffer, T. Chapin, and J. Rockström. 2010. Resilience thinking: integrating resilience, adaptability and transformability. Ecology and Society 15(4):20. https://doi.org/10.5751/ES-03610-150420

Gent, S. E., M. J. C. Crescenzi, E. J. Menninga, and L. Reid. 2015. The reputation trap of NGO accountability. International Theory 7(S3):426-463. https://doi.org/10.1017/S1752971915000159

Green, J., and N. Thorogood. 2014. Qualitative methods for health research. Third edition. Sage, London, UK.

Hebinck, A., J. M. Vervoort, P. Hebinck, L. Rutting, and F. Galli. 2018. Imagining transformative futures: participatory foresight for food systems change. Ecology and Society 23(2):16. https:// doi.org/10.5751/ES-10054-230216

Helfgott, A. 2018. Operationalizing systemic resilience. European Journal of Operational Research 268(3):852-864.https://doi. org/10.1016/j.ejor.2017.11.056

Khanlou, N., and E. Peter. 2005. Participatory action research: considerations for ethical review. Social Science and Medicine 60 (10):2333-2340. https://doi.org/10.1016/j.socscimed.2004.10.004

McCarthy, D. D. P., D. D. Crandall, G. S. Whitelaw, Z. General, and L. J. S. Tsuji. 2011. A critical systems approach to social learning: building adaptive capacity in social, ecological, epistemological (SEE) systems. Ecology and Society 16(3):18. https://doi.org/10.5751/ES-04255-160318

McIntyre-Mills, J. 2008. Making a difference through egovernance from below: an evaluation and future directions. In D. Ing, G. Metcalf, J. Wilby, A. Laszlo, P. Buckle, L. Rasmussen, S. Segawa, and C. Welch, editors. Proceedings of the 52nd Annual Meeting of the ISSS. International Society for the System Sciences, Pockllington, UK. [online] URL: http://journals.isss. org/index.php/proceedings52nd/article/view/1028/356

Midgley, G. 2000. Systemic intervention: philosophy, methodology, and practice. Springer, New York, New York, USA.

Midgley, G. 2016. Moving beyond value conflicts: systemic problem structuring in action. Research memorandum 96. University of Hull, Hull, UK. [online] URL: https://hull-repository.worktribe. com/output/443753/moving-beyond-value-conflicts-systemic-problemstructuring-in-action

Migchelbrink, F. 2018. De kern van participatief actieonderzoek. B.V. Uitgeverij SWP, Amsterdam, The Netherlands.

Ostrom, E. 2007. A diagnostic approach for going beyond panaceas. Proceedings of the National Academy of Sciences 104 (39):15181-15187. https://doi.org/10.1073/pnas.0702288104

Ostrom, E. 2009. A general framework for analyzing sustainability of social-ecological systems. Science 325 (5939):419-422. http://dx.doi.org/10.1126/science.1172133

Pahl-Wostl, C., and M. Hare. 2004. Processes of social learning in integrated resources management. Journal of Community and Applied Social Psychology 14(3):193-206. https://doi.org/10.1002/ casp.774

Pereira, L. M., T. Karpouzoglou, N. Frantzeskaki, and P. Olsson. 2018. Designing transformative spaces for sustainability in social- 
ecological systems. Ecology and Society 23(4):32 https://doi. org/10.5751/ES-10607-230432

Preiser, R., R. Biggs, A. De Vos, and C. Folke. 2018. Socialecological systems as complex adaptive systems: organizing principles for advancing research methods and approaches. Ecology and Society 23(4):46. https://doi.org/10.5751/ES-10558-230446

Raymaker, D. M. 2016. Intersections of critical systems thinking and community based participatory research: a learning organization example with the autistic community. Systemic Practice and Action Research 29(5):405-423. https://doi. org/10.1007/s11213-016-9376-5

Risal, S. 2014. Mismatch between NGO services and beneficiaries' priorities: examining contextual realities. Development in Practice 24(7):883-896. https://doi.org/10.1080/09614524.2014.950190

Roff, G., C. Doropoulos, A. Rogers, Y.-M. Bozec, N. C. Krueck, E. Aurellado, M. Priest, C. Birell, and P. J. Mumby. 2016. The ecological role of sharks on coral reefs. Trends in Ecology and Evolution 31(5):395-407. https://doi.org/10.1016/j.tree.2016.02.014

Sendzimir, J., P. Magnuszewski, and L. Gunderson. 2018. Adaptive management of riverine socio-ecological systems. Pages 301-324 in S. Schmutz and J. Sendimir, editors. Riverine ecosystem management. Springer, Cham, Switzerland. https://doi. org/10.1007/978-3-319-73250-3 16

Shirk, J. L., H. L. Ballard, C. C. Wilderman, T. Phillips, A. Wiggins, R. Jordan, E. McCallie, M. Minarchek, B. V. Lewenstein, M. E. Krasny, and R. Bonney. 2012. Public participation in scientific research: a framework for deliberate design. Ecology and Society 17(2):29. https://doi.org/10.5751/ ES-04705-170229

Sirolli, E. 1998. Ripples from the Zambezi. New Society Publishers, Gabriola Island, Canada.

Stephens, A. 2013. Principled success: eco-feminism and systems thinking come together for better project outcomes. International Journal of Managing Projects in Business 6(1):199-209. https:// doi.org/10.1108/17538371311291099

Stringer, E. T. 2014. Action research. Fourth edition. Sage, Thousand Oaks, California, USA.

Tàbara, J. D., X. Dai, G. Jia, D. McEvoy, H. Neufeldt, A. Serra, S. Werners, and J. J. West. 2010. The climate learning ladder. A pragmatic procedure to support climate adaptation. Environmental Policy and Governance 20(1):1-11. https://doi.org/10.1002/ eet. 530

Trimble, M., and M. Lázaro. 2014. Evaluation criteria for participatory research: insights from coastal Uruguay. Environmental Management 54(1):122-137. https://doi.org/10.1007/ $\underline{\mathrm{s} 00267-014-0276-0}$

Ulrich, W. 1993. Some difficulties of ecological thinking, considered from a critical systems perspective: a plea for critical holism. Systems Practice 6(6):583-611. https://doi.org/10.1007/ $\underline{B F 01059480}$

van Eeten, M. 1999. Dialogues of the deaf: defining new agendas for environmental deadlocks. Eburon, Delft, The Netherlands. van Laerhoven, F., and K. P. Andersson. 2013. The virtue of conflict: an institutional approach to the study of conflict in community forest governance. International Forestry Review 15 (1):122-135. https://doi.org/10.1505/146554813805927219

Vervoort, J. M., L. Rutting, K. Kok, F. L. P. Hermans, T. Veldkamp, A. K. Bregt, and R. van Lammeren. 2012. Exploring dimensions, scales, and cross-scale dynamics from the perspectives of change agents in social-ecological systems. Ecology and Society 17(4):24. https://doi.org/10.5751/ES-05098-170424

Watkins, C., J. Zavaleta, S. Wilson, and S. Francisco. 2018. Developing an interdisciplinary and cross-sectoral community of practice in the domain of forests and livelihoods. Conservation Biology 32(1):60-71. https://doi.org/10.1111/cobi.12982

Weaver, P. M., and J. Rotmans. 2006. Integrated sustainability assessment: What is it, why do it and how? International Journal of Innovation and Sustainable Development 1(4):284-303. https:// doi.org/10.1504/IJISD.2006.013732

Wilson, J. 2017. Paradoxical utopia: the Millennium Villages Project in theory and practice. Journal of Agrarian Change 17 (1):122-143. https://doi.org/10.1111/joac.12133 